\title{
A Clinical Comparative Study of Oral Aprepitant and Injection Palonosetron for Prevention of Postoperative Nausea and Vomiting in Patients of Laparoscopic Cholecystectomy under General Anaesthesia
}

\author{
Agrawal J*, Harioudh V, Goyal P, Mittal R, Choudhary B \\ Department of Anaesthesiology, Pain \& Critical Care, G. R. Medical College, Gwalior, \\ (M.P) India
}

*Corresponding author: Dr. Jitendra Agrawal, Department of Anaesthesiology Gajra

\section{Research Article \\ Volume 4 Issue 1}

Received Date: January 06, 2019

Published Date: February 14, 2019

Raja Medical College Gwalior 474009 M.P, India, Tel: 9300009942; Email: drjagrawal@gmail.com

\section{Abstract}

Aim: To assess and evaluate effect of oral aprepitant and injection palonosetron for prevention of post-operative nausea vomiting [PONV] in patients posted for laparoscopic cholecystectomy under general anaesthesia.

Background: Laparoscopic surgeries have been performed now a day's very frequently. The patients undergoing laparoscopic cholecystectomy under general anaesthesia have high risk for post-operative nausea and vomiting [PONV] with incidence up to $75 \%$.

Method: 90 patients of ASA grade I and II undergoing laparoscopic cholecystectomy were registered for this study. They were divided randomly into 3 groups of 30 each who received 1capsule (80 mg) aprepitant orally 3 hrs before and $2 \mathrm{ml}$ of normal saline IV 10 minute prior to induction in group A, or 1capsule (80 mg) aprepitant orally 3 hrs before and $2 \mathrm{ml}$ of normal saline IV 10 minute prior to induction in group P and placebo 1 capsule orally 3 hrs before and $2 \mathrm{ml}$ of normal saline intravenous (IV) 10 minute prior to induction in group C. After extubation patients were watched and monitored for nausea, retching and vomiting for $30 \mathrm{~min}$., 60min, 2 hour, 6 hour, 12 hour, and 24 hour in postoperative period.

Results: Palonosetron and Aprepitant both are the effective in reducing the incidence of post-operative nausea and vomiting up to 24 hours, when given prior to induction of general anaesthesia. Aprepitant is more effective than Palonosetron in reducing the nausea and vomiting in post-operative period.

Keywords: Laparoscopic Cholecystectomy; Nausea; Vomiting; General Anaesthesia 


\section{Anaesthesia \& Critical Care Medicine Journal}

Abbreviations: HR: Heart Rate; SBP: Systolic Blood Pressure; DBP: Diastolic Blood Pressure; MAP: Mean Arterial Pressure.

\section{Introduction}

Nausea and vomiting is one of the commonest problems experienced by patients in postoperative period. During recovery from general anaesthesia $20-30 \%$ of adult patients have emesis and $0.1 \%$ has severe nausea and vomiting in absence of antiemetic medication preoperatively [1]. It affects the patients in many ways either they are in terms of physical, surgical and anaesthetic complications or may be psychological as well as financial. Therefore prophylactic antiemetic therapy is essential for all these patients [2]. In ambulatory surgery and minor surgery nausea and vomiting is more distressing because of delay in hospital discharge. There are number of factors which make the patients prone to develop PONV such as female sex, obesity, anxiety, history of motion sickness, or previous postoperative vomiting, gastro paresis, abdominal surgery, use of opioids etc [3].

The risk and incidence of postoperative nausea and vomiting is particularly higher in laparoscopic surgery due to stimulation of mechanoreceptors in the gut by pneumoperitoneum [4]. Palonosetron is a long acting "second generation" 5HT3 receptor antagonist has the highest binding affinity to the 5HT3 receptor and approximately 40 hours elimination half- life $[5,6]$. The use of 5HT3 antagonists in the control of PONV proved to be beneficial by selectively blocking these receptors. Aprepitant is the first NK-1 receptor antagonist available for clinical use as an antiemetic. It is a highly selective, brain penetrating NK-1 antagonist with a long half -life of 9-12 hour and preclinical efficacy against opioids induced emesis $[7,8]$.

\section{Methods}

After obtaining approval from the ethical committee, the present study was carried out on 90 patients of ASA grade I and II between age group 20 to 60 years of either sex, posted for laparoscopic cholecystectomy under general anaesthesia in the Department of Anaesthesiology, J.A Group of Hospitals of G.R. Medical College, Gwalior (M.P) after obtaining well informed written consent from the patients. Patients were divided randomly into 3groups, $(\mathrm{n}=30$ each), using closed envelope technique. Group A received 1capsule ( $80 \mathrm{mg}$ ) aprepitant orally $3 \mathrm{hrs}$ before and $2 \mathrm{ml}$ of normal saline IV 10 minute prior to induction, Group'P' received 1capsule (80 mg) aprepitant orally $3 \mathrm{hrs}$ before and $2 \mathrm{ml}$ of normal saline IV 10 minute prior to induction and Group ' $\mathrm{C}$ ' received placebo 1 capsule orally $3 \mathrm{hrs}$ before and $2 \mathrm{ml}$ of normal saline intravenous (IV) 10 minute prior to induction. All the patients were kept overnight fasting. All patients received uniform premedication of inj. Glycopyrrolate $0.2 \mathrm{mg}$. IM 30 minutes before the induction of anaesthesia. Upon arrival of the patient in the operation room, intravenous access with 18G cannula was established. $500 \mathrm{ml}$. of crystalloid infusion was started. All the hemodynamic parameters heart rate (HR), systolic blood pressure (SBP) diastolic blood pressure (DBP) mean arterial pressure (MAP) and Oxygen saturation (Spo2) were monitored and recorded. Oral capsule of the study drug was given $3 \mathrm{hrs}$ before and injection of study drug was given intravenously slowly $10 \mathrm{~min}$ before induction of anaesthesia as per study protocol.

After $10 \mathrm{~min}$. inj pentatonic $0.3-0.6 \mathrm{mg} / \mathrm{kg}$. IV followed by inj. thiopentone sodium $3-5 \mathrm{mg} / \mathrm{kg} \mathrm{BW}$, intravenously subsequently IV inj. Succinylcholine $1-1.5 \mathrm{mg} / \mathrm{kg}$ BW was given. IPPV with $100 \%$ was done for 60 seconds followed by laryngoscopy and endotracheal intubation with a suitable size of cuffed endotracheal tube. Anaesthesia was maintained with $\mathrm{N}_{2} \mathrm{O} 66 \%$ and $\mathrm{O}_{2} 33 \%$ and intermittent Isoflurane with controlled ventilation by using nondepolarizing muscle relaxant injection Atracurium 0.25 $\mathrm{mg} / \mathrm{kg}$ BW bolus and maintenance dose $0.1 \mathrm{mg} \mathrm{kg}$ of BW. At the end of surgical procedure residual effect of muscle relaxant was reversed with a combination of inj glycopyrrolate $0.5 \mathrm{mg}$ and inj neostigmine $2.5 \mathrm{mg}$.

After extubation patients were further oxygenated for $5 \mathrm{~min}$. and after complete recovery patients were shifted to postoperative ward. In post-operative ward each patient was monitored for nausea, retching and vomiting for $30 \mathrm{~min} ., 60 \mathrm{~min}, 2$ hour, 6 hour, 12 hour, and 24 hour. Rescue antiemetic inj metoclopramide $10 \mathrm{mg}$ IV slow was given if the patient had more than one episode of vomiting or retching, if patient had nausea lasting longer than 15 minutes.

\section{Statistical Analysis}

Obtained data were tabulated and subjected to statistical analysis by using Epi.info version 7-0 statistic software.

\section{Results}

As shown in tables 1 and 2, the drug response in preventing nausea and vomiting was maximum in group 


\section{Anaesthesia \& Critical Care Medicine Journal}

A, followed by group $\mathrm{P}$, and was minimum in group $\mathrm{C}$. The number of patients free from nausea and vomiting was

increasing and was maximum at $24 \mathrm{hrs}$ after the surgery.

\begin{tabular}{|c|c|c|c|c|c|c|}
\hline Duration & \multicolumn{2}{|c|}{ Group C } & \multicolumn{2}{c|}{ Group P } & \multicolumn{2}{c|}{ Group A } \\
\hline & No. & \% & No. & \% & No. & \% \\
\hline 30 min. & 17 & 56.67 & 22 & 73.34 & 27 & 90.0 \\
\hline 60 min. & 18 & 60 & 22 & 73.34 & 26 & 86.67 \\
\hline 2 hours & 20 & 66.67 & 24 & 80 & 28 & 93.34 \\
\hline 6 hours & 20 & 66.67 & 25 & 83.34 & 27 & 90.0 \\
\hline 12 hours & 23 & 76.67 & 27 & 90.0 & 28 & 93.34 \\
\hline 24 hours & 24 & 80 & 28 & 93.34 & 28 & 93.34 \\
\hline p value & \multicolumn{2}{|c|}{$\mathbf{0 . 3 3}$} & $\mathbf{0 . 2 1}$ & \multicolumn{2}{c|}{$\mathbf{0 . 9 2}$} \\
\hline
\end{tabular}

Table 1: Drug response to prevent nausea (nausea free patients)

\begin{tabular}{|c|c|c|c|c|c|c|}
\hline Duration & \multicolumn{2}{|c|}{ Group C } & \multicolumn{2}{c|}{ Group P } & \multicolumn{2}{c|}{ Group A } \\
\hline & No. & $\mathbf{0}$ & No. & $\mathbf{\%}$ & No. & \% \\
\hline 30 min. & 23 & 76.67 & 26 & 86.67 & 28 & 93.34 \\
\hline 60 min. & 23 & 76.67 & 25 & 83.34 & 29 & 96.67 \\
\hline 2 hours & 24 & 80 & 27 & 90 & 29 & 96.67 \\
\hline 6 hours & 25 & 83.34 & 27 & 90 & 30 & 100 \\
\hline 12 hours & 26 & 86.67 & 27 & 90 & 29 & 96.67 \\
\hline 24 hours & 26 & 86.67 & 29 & 96.67 & 29 & 96.67 \\
\hline p value & \multicolumn{3}{|c|}{$\mathbf{0 . 9 7}$} & \multicolumn{3}{|c|}{$\mathbf{0 8}$} \\
\hline
\end{tabular}

Table 2: Vomiting free patients in different groups

Aprepitant was found to be more effective in prevention of PONV than Palonosetron as the incidence of the PONV was significantly lesser with Aprepitant $(\mathrm{p}<0.05)$, during entire observation period $(0-24 \mathrm{hrs})$ (Table3). However, no difference was found in rescue drug requirement between two drugs.

The percentage of patients, requiring rescue drug, during observation period for group $\mathrm{C}, \mathrm{P}$, and $\mathrm{R}$ was $66.0 \%, 23.34 \%$, and $13.34 \%$ respectively.

\begin{tabular}{|c|c|c|c|c|c|}
\hline Groups & No. & $\%$ & c2 & P value & Significance \\
\hline C & 10 & 33.34 & \multirow{2}{*}{4.29} & \multirow{2}{*}{0.03} & \multirow{2}{*}{ S } \\
\hline $\mathbf{P}$ & 18 & 60 & & & \\
\hline $\mathrm{C}$ & 10 & 33.34 & \multirow{2}{*}{15.43} & \multirow{2}{*}{0.00008} & \multirow{2}{*}{ S } \\
\hline A & 25 & 83.34 & & & \\
\hline $\mathbf{P}$ & 18 & 60 & \multirow{2}{*}{4.02} & \multirow{2}{*}{0.04} & \multirow{2}{*}{$\mathrm{S}$} \\
\hline A & 25 & 83.34 & & & \\
\hline
\end{tabular}

Table 3: Statistical Analysis - Vomiting free patients (Intergroup comparison)

\section{Discussion}

PONV is still very common and distressing complication after laparoscopic cholecystectomy with incidence between 60\%-71\% [9]. Emetic response in PONV is very complex and is triggered by multiple inputs that arrive from areas, such as the higher cortical centers, cerebellum, vestibular apparatus, glossopharyngeal and vagal afferent nerve. A variety of neurotransmitter and receptor systems including histaminergic, cholinergic, dopaminergic, neurokininergic and serotonergic mediate these signals. Peripheral 5-HT3 receptors are in vagal terminals linked to the vomiting center, and competitive 5-HT3 antagonists can block initiation of the vomiting reflex at these sites and has been used widely for prevention of PONV [10]. Efficacy of 5HT-3 receptor antagonists like ondansetron, Granisetron and palonosetron has been studied with or without 


\section{Anaesthesia \& Critical Care Medicine Journal}

dexamethasone for control of PONV and have yielded mixed results [11-13].

Aprepitant, selective NK-1 receptor antagonist, with 9 to 14 hrs half-life time has been studied for prevention of PONV. It acts by, blocking the emetic effects of substance $P$ in the gastrointestinal tract and nucleus tractus solitaries in brain [14]. Aprepitant has long half-life and has demonstrated efficacy against nausea and vomiting according to studies focused on chemotherapy CINV in combination with other antiemetic drugs $[15,16]$. In this randomized, double-blind, clinical study, we evaluated the response and efficacy of single IV dose of 5HT3 receptor antagonist, palonosetron and compared it with oral Aprepitant for prevention of PONV. In our study, the mean age, sex ,mean weight, and mean duration of surgery for each group were comparable as age, obesity, duration of surgery, female sex etc. are well known risk factors for PONV and since we used placebo in this study, patients with high risk factors were not given priority in our study. The drug response in preventing nausea and vomiting was maximum in Aprepitant group, followed by Palonosetron group. The number of patients free from nausea and vomiting was increasing and was maximum at $24 \mathrm{hrs}$ after the surgery; however it was statistically not significant $(p>0.05)$. Aprepitant was found to be more effective in prevention of PONV than Palonosetron as the incidence of the PONV was significantly lesser with Aprepitant $(\mathrm{p}<0.05)$, during entire observation period $(0$ $24 \mathrm{hrs}$ ). However, no difference was found in rescue drug requirement between two drugs. This is confronted by a study conducted by Moon H Y et al [17]. In which they equated Palonosetron with Aprepitant in prevention of PONV.

This difference in results between both the studies may have attributed to few facts: First, higher dose of Aprepitant ( $80 \mathrm{mg}$ ) was used in our study, whereas it was $40 \mathrm{mg}$ in theirs. The reason behind this discrepancy is that the optimal dose of Aprepitant, sufficient to prevent PONV is still to be established, which is endorsed by Jung, et al. [18], Diemunsch, et al. [19], second, they used Propofol for induction while we used Thiopentone sodium. To date, Propofol's antiemetic activity has already been established by the virtue of its serotonergic antagonistic activity, which increases the antiemetic property of Palonosetron synergistically $[20,21]$. The side effects with Aprepitant and palonosetron were transient $\&$ mild and the most common adverse effects experienced by patients in group A and group P was headache and constipation. Dizziness was observed by one patient each in all the three groups. These adverse effects were of no clinical significance. Hence it could easily be inferred that as far as side effects are concerned, both the drugs are generally safe.

\section{Conclusion}

Although Palonosetron and Aprepitant both are safe and effective due to specific action and minimum side effects Aprepitant $80 \mathrm{mg}$ oral was found to be more effective and superior than a single injection Palonosetron $0.075 \mathrm{mg} \mathrm{I} / \mathrm{V}$.

\section{Limitations}

We did not include patients at high risk of postoperative nausea \&vomiting also we did not follow patients once discharged from the hospital. Post discharge nausea and vomiting (PDNV) was not studied.

Further research is needed to study the efficacy, safety profile and optimum dosage in different age groups in Indian population.

\section{References}

1. Kaur U, Sharma VK, Sidhu JS (2014) A comparison of aprepitant and ondansetron in prophylaxis of postoperative nausea and vomiting in laparoscopic cholecystectomy. Sch J App Med Sci 2(3B): 10201027.

2. Gupta V, Wakhloo R, Lahori V, Mahajan M, Gupta S (2008) Prophylactic Antiemetic Therapy With Ondansetron, Granisetron And Metoclopramide In Patients Undergoing Laparoscopic Cholecystectomy Under General Anaesthesia. The Internet Journal of Anesthesiology 10(2): 1-4.

3. Sarkar M, Pawa A, Dewoolkar L, Charan (2006) Comparative study of single dose intravenous ondansetron and metoclopramide as a premedication for prevention of postoperative nausea and vomiting in obstetrical laparoscopic surgery under general anaesthesia. The Internet Journal of Anesthesiology 13(2): 1-5.

4. Islam S, Jain PN (2004) Postoperative nausea and vomiting (PONV): A review article. Indian J Anaesth 48(4): 253-258.

5. Shadangi BK, Agrawal J, Pandey R, Kumar A, Jain S, et al. (2013) A prospective, randomized, double-blind, 


\section{Anaesthesia \& Critical Care Medicine Journal}

comparative study of the efficacy of intravenous ondansetron and palonosetron for prevention of postoperative nausea and vomiting. Anesth, Pain \& Intensive Care 17(1): 55-58.

6. Wallenborn J, Kranke P (2012) Palonosetron hydrochloride in the prevention and treatment of postoperative nausea and vomiting. Clinical Medicine Insights: Therapeutics 2: 387-396.

7. Kakuta N, Tsutsumi YM, Horikawa YT, Kawano H, Kinoshita M, et al. (2011) Neurokinin-1 receptor antagonism, aprepitant, effectively diminishes postoperative nausea and vomiting while increasing analgesic tolerance in laparoscopic gynecological procedures. The Journal of Medical Investigation 58(3-45): 246-251.

8. Gan TJ, Apfel CC, Kovac A, Philip BK, Singla N, et al. (2007) A randomized, double-blind comparison of the NK1 antagonist, aprepitant, versus ondansetron for the prevention of postoperative nausea and vomiting. Anesth Analg 104(5): 1082-1089.

9. Monohar PS, Eshori L, Singh LD, Singh NR, Rajkumar G, et al. (2017) A comparative study of the antiemetic effect of intravenous palonosetron with granisetron for the prevention of postoperative nausea and vomiting following laparoscopic cholecystectomy under general anaesthesia. J Med Soc 31(2): 114-118.

10. Apfel CC (2010) Postoperative nausea and vomiting. In: Miller RD, editor (Eds.) Miller's anesthesia ( $7^{\text {th }}$ edn), Philadelphia: Churchill Livingstone, pp. 27292755.

11. TM (2003) Granisetron: New insights into its use for the treatment of chemotherapy induced nausea and vomiting. Expert Opin Pharmacotherapy 4(9): 15631571.

12. Fujii Y, Tanaka H, Kawasaki T (2004) Effects of Granisetron in the treatment of nausea and vomiting after laparoscopic cholecystectomy: adose ranging study. Clin Ther 26(7): 1055-1060.

13. Dua N, Bhatanagar S, Mishra S, Singhal AK (2004) Granisetron and Ondansetron for the prevention of nausea and vomiting in patients undergoing modified radical mastectomy. Anaesth Intensive Care 32(6): 761-764.
14. Green MS, Green P, Malayaman SN, Hepler M, Neubert LJ, et al. (2012) A Randomized, Double - blind comparison of oral Aprepitant alone vs oral Aprepitant and transdermal Scopolamine for preventing postoperative nausea and vomiting. $\mathrm{Br} \mathrm{J}$ Anaesth109 (5): 716-722.

15. Longo F, Mansueto G, Lapadula V, De Sanctis R, Quadrini S, et al. (2011) Palonosetron plus 3-day Aprepitant and Dexamethasone to prevent nausea and vomiting in patients receiving highly emetogenic chemotherapy. Support Care Cancer 19(8): 11591164.

16. Liu M, Zhang H, du BX, Xu FY, Zou Z et al. (2015) Neurokinin-1 receptor antagonists in preventing postoperative nausea and vomiting. Medicine (Baltimore) 94(19): e762.

17. Moon HY, Baek CW, Choi GJ, Shin HY, Kang Y, et al. (2014) Palonosetron and aprepitant for the prevention of postoperative nausea and vomiting in patients indicated for laparoscopic gynaecologic surgery: a double-blind randomised trial. BMC Anesthesiology 14: 68.

18. Jung WS, Kim YB, Park HY, Choi WJ, Yang HS (2013) Oral administration of aprepitant to prevent postoperative nausea in high susceptible patients after gynecological laparoscopy. Journal of Anesthesia 27(3): 396-401.

19. Diemunsch P, Gan TJ, Philip BK, Girao MJ, Eberhart L, et al. (2007) Single-dose aprepitant vs ondansetron for the prevention of postoperative nausea and vomiting: a randomized, double-blind phase III trial in patients undergoing open abdominal surgery. British Journal of Anaesthesia 99(2): 202-211.

20. Turgut HC, Arslan M (2016) An overview of treatment options for postoperative nausea and vomiting after laparoscopic surgical procedures. Anaesth Pain \& Intensive Care 20(2): 193-200.

21. Kim EG, Park HJ, Kang H, Choi J, Lee HJ (2014) Antiemetic effect of propofol administered at the end of surgery in laparoscopic assisted vaginal hyster ectomy. Korean J Anesthesiol 66(3): 210-215. 